\title{
A prey chamber for the experimental analysis of raptor hunting
}

\author{
CARL D. CHENEY \\ Department of Psychology and Institute of Animal Behavior, Utah State University, Logan, Utah 84322
}

A chamber is described for use with raptorial birds and live prey. The chamber is equipped with visual and physical access doors and is designed to be operated in conjunction with an instrumented perch and electromechanical programming equipment. The search, detection, pursuit, and capture components of a hunting episode are separable with this system; participation by the raptor in each component can be controlled and measured.

We have been interested in the behavioral strategies employed by birds of prey during the search phase of a hunting trial, that is, prior to the detection of prey. What variables control where a raptor hunts when given alternative hunting areas? Foraging strategy involves such behavioral concepts as reward following, maximizing, matching, hunting effort vs. prey availability, profitability, switching, and so on: Our interest in the problem led to the construction of the prey chamber described here.

The characteristics of prey animals that elicit attack by raptorial birds have been reported (e.g., Ruggiero, Cheney, \& Knowlton, 1979; Snyder, Jenson, \& Cheney, 1976; Sparrowe, 1972). Experimental trials in these studies usually begin with the raptor perched and the prey items, exhibiting various prey characteristics, presented some distance away. Latency to strike or prey selected when multiple choices are provided typically' serve as the dependent measures. The work described in this paper begins with an earlier step, namely, where does the raptor go to hunt in the first place?

\section{PREDATION CHAIN}

A predatory hunting episode may be analyzed into phases: search, detection, pursuit, capture, and kill (Cheney \& Snyder, 1974). Variables controlling predator activity in each of these phases have not usually been manipulated separately. Yet, in order to better understand predator ecology, it is critical to systematically observe the variables controlling predator behavior. For example, why does a particular predator hunt in a specific region in contrast to any other region? Does the hunter simply return to the location associated with its most recent success? Or does the animal develop a strategy involving probability matching, profitability, or random switching? By categorizing a hunting episode

The author is indebted to Jed Merrill for construction and help in designing the chamber. Reprint requests may be sent to the author, UMC 28, Utah State University, Logan, Utah 84322. into the five phases noted earlier and arranging for the mechanical definition of behavior and stimulus events in each phase, it is possible to detect the development of a strategy and to qualitatively specify its parameters. Also, organizing a hunting episode into phases of behavior that occur under related and sequential stimulus events clarifies the episode as an example of a behavior chain. Such a chain is depicted in Figure 1.

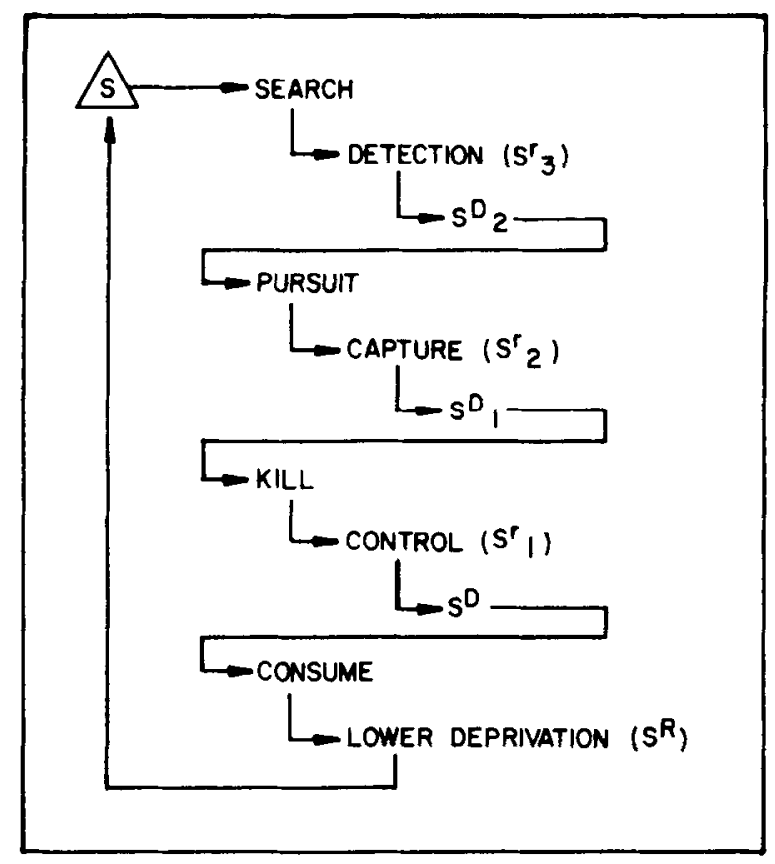

Figure 1. A diagramatic foraging episode of a typical predator in terms of behavior, reinforcers, and setting conditions (discriminative stimuli, $S^{D}$ ). The animal begins searching because of unknown state conditions (possibly hours of deprivation) and may be reinforced (Sr3) by detecting a prey item. Such detection sets the occasion (becomes $S^{D}$ ) for pursuit. This activity is consequated (reinforced, $S^{r}$ ) by capture, which then sets the occasion ( $S^{\left.D_{1}\right)}$ for killing responses that are reinforced $\left(S^{x_{1}}\right)$ by the prey item's no longer struggling. This control over the prey becomes an $S D$ for consumption, which provides the ultimate reinforcer (SR). 
The animal begins in some state condition at $S$ and starts to search. The reinforcement for searching is prey detection, which also sets the occasion (becomes a discriminative stimulus) for pursuit. Reinforcement for pursuit is capture, and the prey item in hand sets the occasion for killing. A nonstruggling prey item may be consumed. This lowers deprivation and influences the state condition, which in turn may preclude further searching. It is not always the case, however, that consumption follows a kill (Toner, 1956). Therefore, in Figure 1 the reinforcer is considered to be lowered deprivation, which may not be hunger.

\section{CHAMBER CONSTRUCTION}

The prey chamber (see Figures 2 and 3 ) provides a method for restricting hunting areas, separating visual from physical access to the prey arena (i.e., inside the chamber), and specifying hunting (i.e., search and pursuit) and hunting effort (i.e., time on the perch). Each chamber has a $127-\mathrm{cm}$-high perch fitted with a microswitch ( $M$ in Figure 2) such that the birds' presence can be automatically detected and recorded. The prey chamber is a $77 \times 77 \times 30 \mathrm{~cm}$ box equipped with both an outer solid wooden lid and an inner clear Plexiglas lid (Points A and B in Figures 2 and 3). The top lid is of solid 6-mm plywood and restricts visual and physical access to the box interior. Programming apparatus can provide for this door to open when the associated perch is activated. A spring (Point $\mathrm{C}$ in Figure 2) on the chamber side raises the rear-hinged top lid in less than $2 \mathrm{sec}$ when the solenoid latch (Point D) is activated. Immediately below this plywood lid is the clear Plexiglas
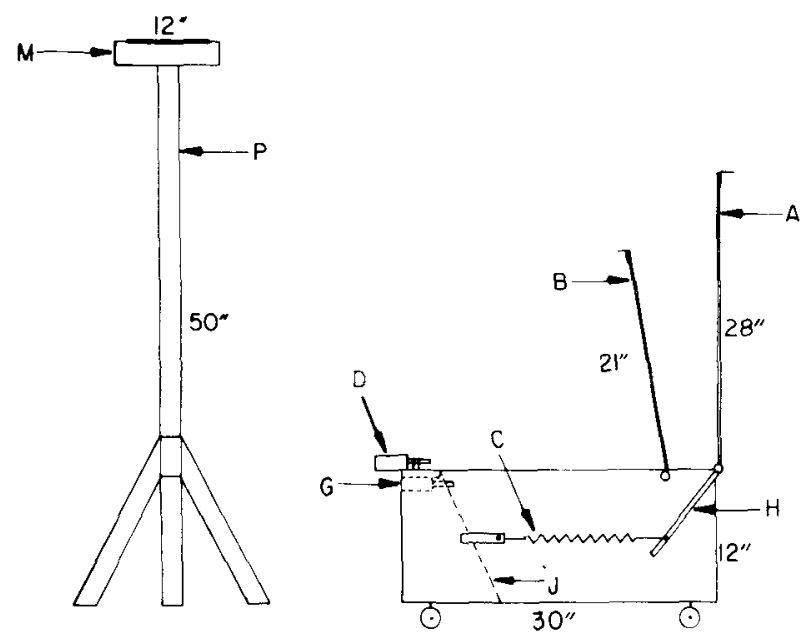

Figure 2. Left side of the prey chamber with both lids up. Spring $C$ opens lid A when solenoid D is activated. The perch $P$ is shown in front of the chamber. Interior wall $J$ restricts prey access to portions of the box visible from perch $M$.

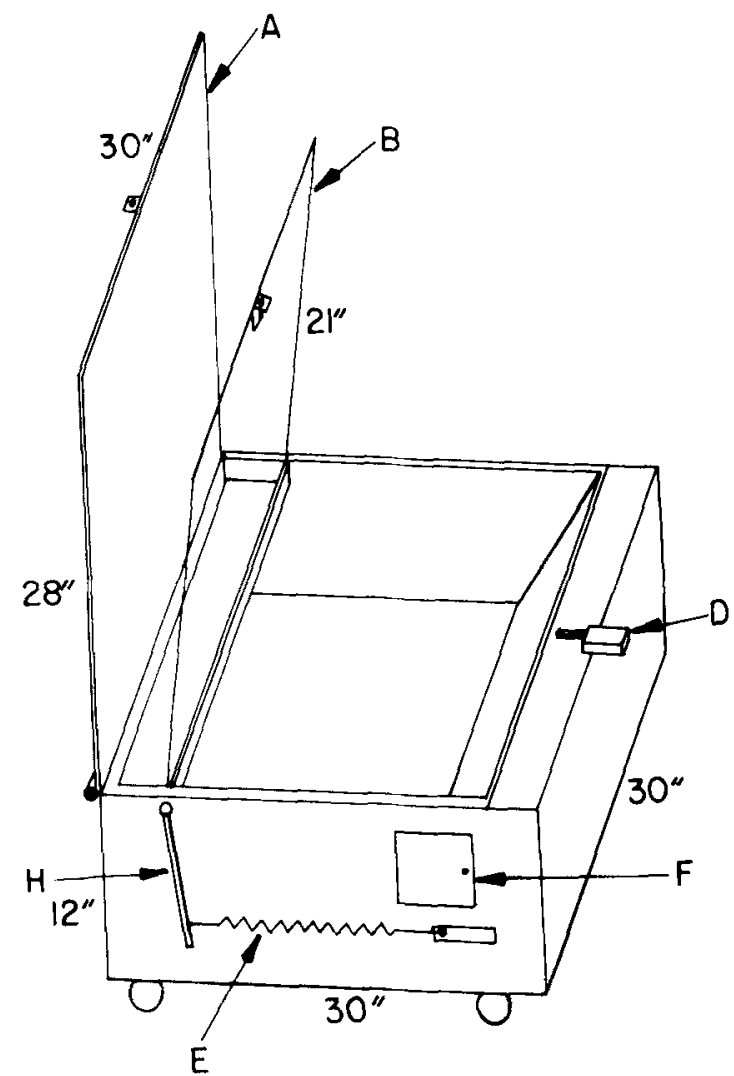

Figure 3. Right front elevation of the chamber showing lever arm $H$ connected to spring $E$ that opens lid $B$ when solenoid $G$ (Figure 2) is activated. The door $F$ allows setting the internal solenoid $\mathrm{G}$.

lid (B), which also prohibits physical access but allows visual access to the box interior. The small access door (Point F, Figure 3) allows the operator to set the solenoid $(G)$ on the inside (Plexiglas) door. The two lids define and differentiate search from detection. The bird may visually "search" any of the chambers provided by landing on the perch located in front of that chamber for any required period of time. The top (solid) lid opens and the bird may detect a potential prey item. This detection is the reinforcer for a searching response. Additional time on the perch in the presence of a detected prey is analogous to pursuit and is consequated (reinforced) by the Plexiglas lid opening to allow chamber entry and prey capture. If detection discloses that the chamber is empty or contains a nonpreferred item, search may be resumed by the bird's flying to a different area (perch). The foraging process from search to consumption is considered to be a heterogeneous behavior chain with discriminative stimuli and reinforcement at every link (e.g., Chance, 1979, p. 98).

\section{CHAMBER USE}

One study using these chambers investigated the 
influence of differential prey probability within a specific area on raptor search patterns (Mueller, 1976). In this study one chamber of the three available on every trial always held a live white Mus musculus. However, the probability of a chamber containing an item changed across 30 to 50 trials. Chamber 1 held a mouse $60 \%$ of the time, Chamber 2, 30\%, and Chamber $3,10 \%$. Five seconds on the perch were required for the visual access door to open, and $5 \mathrm{sec}$ more were necessary for physical access to the chamber interior.

The experimental question was, over an extended series of trials, to which chamber is the bird most likely to go? Of major interest was whether the birds would match responses to reinforcement probability or maximize by selecting the highest probability chamber on every trial.

We have also conducted studies involving the manipulation of raptor-prey proximity, prey position from raptor starting point, and prey type. These investigations dealt with nearness or orientation of search area as variables contributing to foraging strategy, position habits, and prey preferences. Relative prey value was determined by attaching differential response costs to each prey item. Cost was defined by the amount of time the bird was required to remain on the perch during the pursuit phase. For example, a bird could gain access to a larger prey by remaining perched twice as long before being able to open the physical access door.

\section{CONCLUSIONS}

In addition to allowing an objective study of several features of a raptor hunting episode, the chambers have operated reliably more than 1,000 times each, and they have shown little wear. Resetting the solenoids on the door latches (Points D and G) is done by hand after each operation, and these may require occasional adjustment.

\section{REFERENCES}

Chance, P. Learning and behavior. Belmont, Calif: Wadsworth, 1979.

Cheney, C. D., \& SNyder, R. L. A chamber for separating visual and physical prey access from predators. Behavior Research Methods \& Instrumentation, 1974, 6, 553-555.

Mueller, D. L. Probability learning in prey selection with a great horned owl and red-tailed hawk. Unpublished Master's thesis, Utah State University, 1976.

Ruggiero, L. F., Cheney, C. D., \& Knowlton, F. Interacting prey characteristic effects on Kestrel predatory behavior. American Naturalist, 1979, 113, 749-757.

Snyder, R. L., Jenson, W., \& Cheney, C. D. Environmental familiarity and activity: Aspects of prey selection for a Ferruginous hawk. Condor, 1976, 78, 138-139.

Sparrowe, R. D. Prey catching in the sparrow hawk. Journal of Wildlife Management, 1972, 36, 297-306.

Toner, C. G. House cat predation on small mammals. Journal of Mammology, 1956, 37, 119.

(Received for publication May 11, 1979; revision accepted October 30, 1979.) 